\title{
Clinical efficacy of type-B ultrasound-guided intraperitoneal hyperthermic chemoperfusion combined with systemic chemotherapy in advanced gastric cancer patients with malignant ascites
}

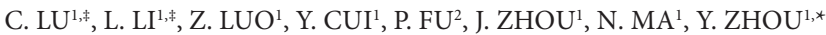 \\ ${ }^{1}$ Department of Oncology, People's Hospital of Zhengzhou University, Zhengzhou, Henan 450003, P.R. China; ${ }^{2}$ Henan Center for Disease Control \\ and Prevention, Zhengzhou, Henan 450003, P.R. China \\ ${ }^{*}$ Correspondence: $z$ ghnsyzlkzy@163.com \\ ${ }^{*}$ Contributed equally to this work.
}

Received June 22, 2015 / Accepted September 23, 2015

\begin{abstract}
Objectives: To evaluate the clinical efficacy of systemic chemotherapy combined with intraperitoneal hyperthermic perfusion in advanced gastric cancer patients with malignant ascites. Patients and Methods: Forty-eight gastric cancer patients with malignant ascites who were admitted to our hospital were selected and randomly divided into the hyperthermic perfusion and control groups. The control group only received systemic chemotherapy, and the hyperthermic perfusion group received systemic chemotherapy combined with intraperitoneal hyperthermic chemoperfusion. The therapeutic efficacy, the survival time and the associated toxicity were determined for the two groups. Results: The efficacy was significantly higher in the hyperthermic perfusion group $(85.7 \%)$ than in the control group $(30.0 \%)(\mathrm{P}<0.05)$. There was no significant difference in the incidence of nausea and vomiting, bone marrow suppression, diarrhea and constipation or liver and kidney damage in the hyperthermic perfusion group compared with the control group $(\mathrm{P}>0.05)$. The median progression-free survival (PFS) was significantly longer in the hyperthermic perfusion group (12 months) compared with the control group (6 months) $(\mathrm{P}<0.05)$. The median overall survival (OS) was significantly longer in the hyperthermic perfusion group $(21$ months) compared with the control group (9 months) $(\mathrm{P}<0.05)$. There was a significantly higher 1-year survival rate in the hyperthermic perfusion group (89.3\%) than in the control group $(36.4 \%)(\mathrm{P}<0.05)$; however, there was no significant difference in the 3 -year survival rate (10.7\% vs. $10.0 \%)$. The Karnofsky Performance Status (KPS) score in the hyperthermic perfusion group increased significantly from $62.8 \pm 1.84$ to $74.3 \pm 5.0$ after hyperthermic chemoperfusion $(\mathrm{P}<0.05)$. Conclusion: Systemic chemotherapy combined with intraperitoneal hyperthermic perfusion exhibited significant clinical efficacy in advanced gastric cancer patients with malignant ascites, helped control ascites, improved the quality of life and extended PFS and OS. This treatment regimen is worth promoting.
\end{abstract}

Key words: gastric cancer, ascites, chemotherapy, intraperitoneal hyperthermic chemoperfusion

Gastric cancer is a malignant disease with high morbidity and mortality. Currently, gastric cancer treatment predominantly involves surgical resection and chemotherapy, which benefits some patients. However, the rates of recurrence and metastasis are high. The most common recurrence of gastric cancer is intraperitoneal metastasis, which tends to form malignant ascites $[1,2]$. These patients have a poor prognosis and a median overall survival (OS) of only 5 months [3]. To a certain extent, effective palliative treatment can reduce the generation of ascites, decrease abdominal pain and bloating and extend $O S$ in advanced cancer patients. In addition, effec- tive palliative treatment has a positive effect on prognosis and can improve the quality of life of patients. Currently, clinical treatments for malignant ascites include diuretics, paracentesis drainage, intraperitoneal chemotherapy and immunotherapy. However, the effects are not satisfactory, and ascites recurrences readily occur.

Intraperitoneal hyperthermic chemoperfusion, which is based on the characteristics of gastric cancer, is an effective treatment for gastric cancer. Based on the different biological characteristics of human tumor cells and normal cells, such as temperature sensitivity, intracellular water content and blood 
flow, hyperthermia has been utilized as a cancer therapy. The heating device in the extracorporeal hyperthermic chemoperfusion system heats the treatment fluid to the treatment temperature, and then, the fluid is pumped into the body cavity via a power circulation pump. The effective treatment temperature is maintained for the duration of the treatment time (for example, 90 minutes) to induce the thermal destruction mechanism; the metastatic cancer cells throughout the plasma are cleared by the heat, and chemotherapy drugs with heat sensitizing effects are added based on the cellular characteristics after hyperthermia, such as cancer cell metabolic dysfunction and genetic damage. The treatment induces the cancer cells to stop dividing, eliminates the lesions caused by malignant effusions, rapidly repairs the plasma membranes, and achieves its primary purpose of effectively treating the malignant effusions $[4,5]$. In 1988, Fujimoto et al. developed an integrated approach combining hyperthermia and intraperitoneal chemotherapy based on the thermodynamic effects of hyperthermia, specifically that hyperthermia can increase anti-cancer drug efficacy. For the first time, they used hyperthermic chemoperfusion technology to treat gastrointestinal malignancies, providing a novel treatment option for gastric cancer. The utilization of hyperthermic chemoperfusion in treating malignant body cavity effusions significantly increases the efficacy. The control rate of body cavity effusions is greater than $80 \%$, which is difficult to achieve with traditional treatments. Recently, body cavity hyperthermic chemoperfusion showed encouraging efficacy in preventing chest, abdomen and pelvic metastases in postoperative patients, effectively delayed tumor recurrence and progression, prolonged $O S$ and increased the quality of life [6-12]. This study selected advanced gastric cancer patients with malignant ascites who were admitted to our hospital and determined the clinical efficacy of intraperitoneal hyperthermic chemoperfusion compared with systemic chemotherapy.

\section{Patients and methods}

General information. The selected 48 gastric cancer patients were admitted to our hospital from Jan. 2010 to Mar.

Table1. Clinical data of patients in two groups $(P>0.05)$

\begin{tabular}{lcc}
\hline & Control group & $\begin{array}{c}\text { Hyperthermic } \\
\text { perfusion group }\end{array}$ \\
\hline Gender(n) & 12 & 15 \\
Male & 8 & 13 \\
Femal & $54.3 \pm 6.6$ & $52.4 \pm 7.9$ \\
Age(years) & & \\
Pathological Grade & 4 & 5 \\
I-II & 16 & 23 \\
III-IV & 14 & 19 \\
gastric cancer & 6 & 9 \\
Esophago-gastric junctioncance & $65.5 \pm 1.98$ & $62.8 \pm 1.84$ \\
KPS & & \\
\hline
\end{tabular}

2011. The disease was diagnosed based on pathology after surgical removal or endoscopic biopsy. All the patients had associated malignant ascites. Type-B ultrasound proved that the ascites volumes were approximately $1000-4000 \mathrm{ml}$. The Karnofsky Performance Status (KPS) scores were between 50 and 80 . The size changes of the primary tumors and the intraperitoneal metastatic tumors were evaluated by computerized tomography (CT). Based on the treatment desires of the patients and their families, the patients were divided into the hyperthermic perfusion group (heated intraoperative intraperitoneal chemotherapy + systemic chemotherapy HIPEC) and the control group (systemic chemotherapy). The hyperthermic perfusion group had 28 patients, and the control group had 20 patients. The median ages of the hyperthermic perfusion group and the control group were 52.4 and 54.3 years, respectively. The above data on the patients in the two groups were comparable (Table 1). All the patients signed the consent form before treatment, and the study was approved by the Ethics Committee at Henan Provincial People's Hospital.

Methods. Patients in the hyperthermic perfusion group were given intraperitoneal hyperthermic chemoperfusion combined with systemic chemotherapy. The patients in the intraperitoneal hyperthermic chemoperfusion group were placed in the supine position after emptying their bladder; a type- $B$ ultrasound-guided abdominal catheter was installed percutaneously. A total of three BR TRG II abdominal drainage tubes (Guangzhou Bright Medical Technology Co.,Ltd,China)were installed. The circulating injections of $1500-2500 \mathrm{ml}$ of hot saline $\left(44^{\circ} \mathrm{C}\right)$, cisplatin (DDP, $40 \mathrm{mg} /$ $\mathrm{m} 2), 5-\mathrm{FU}(500 \mathrm{mg} / \mathrm{m} 2),[13,14]$ and dexamethasone $(10$ mg) were administered using "BR TRG I type high- precision hyperthermic perfusion intraperi-toneal treatment system". (Guangzhou Bright Medical Technology Co.,Ltd,China.) The entire perfusion process took longer than $1.5 \mathrm{~h}$, and the inlet and outlet were under strict temperature control: the outlet was controlled at $41^{\circ} \mathrm{C}$, and the inlet was controlled at $44^{\circ} \mathrm{C}$. The patients received 1 perfusion every other day for a total of 3 perfusions [15]. During the intraperitoneal hyperthermic chemoperfusion period, systemic intravenous chemotherapy was not administered. After three perfusion treatments, Oxaliplatin (Qilu Pharmaceutical (Hainan) Co., Ltd,China)or Docetaxel (Shenzhen Main Luck Pharmaceuticals Inc,China) + Tegafur, Gimeracil and Oteracil Porassium Capsules (Qilu Pharmaceutical (Hainan) Co., Ltd, China)chemotherapy was given for 3 weeks as one cycle.

The patients in the control group underwent a simple paracentesis drainage and received systemic chemotherapy. The chemotherapy regimen was the same as in the hyperthermic perfusion group (the same chemotherapy drugs and doses).

Efficacy evaluation. The clinical responses were categorized as the following: complete response (CR), partial response (PR), stable disease (SD), or progressive disease (PD). A CR was defined as the absence of abdominal ascites 4 weeks after treatment; a PR was defined as a greater than 50\% reduction in abdominal ascites 4 weeks after treatment; SD 


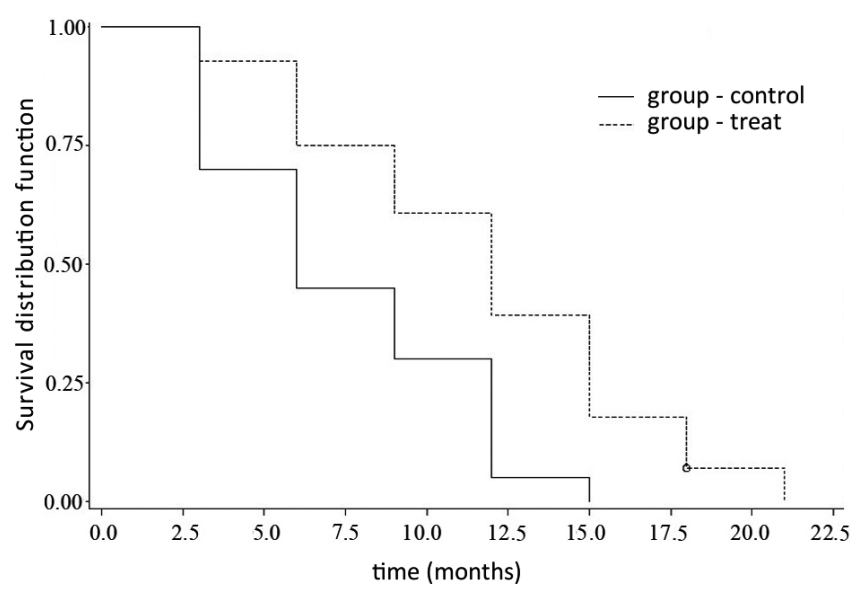

Figure 1. The median PFS in the hyperthermic perfusion group (12 months) was significantly different from that in the control group (6 months) $(\mathrm{P}<0.05)$.

was defined as a less than $50 \%$ reduction in abdominal ascites 4 weeks after treatment; and PD was defined as a greater than $20 \%$ increase in ascites with further aggravation of clinical symptoms or death. The treatment was considered to be effective in patients with either a CR or a PR. The KPS score was used to quantitate the quality of life of the patients.

Side effects. The blood toxicity criteria established by the WHO were used to categorize the side effects (0-IV). During the treatment period, the patients in the two groups were evaluated for side effects such as nausea and vomiting, bone marrow suppression, diarrhea and constipation and liver and kidney damage.

Survival time. The median progression-free survival (PFS), median OS, and 1-year and 3-year survival rates were determined for the patients in the two groups.

Statistical analysis. The data collected from the patients in the two groups were statistically analyzed using SPSS 17.0. The rates were compared using the chi-square test, and the means were compared using the $t$ test. $\mathrm{P}<0.05$ indicates a significant difference.

\section{Results}

The efficacy of chemotherapy. Clinical CR of ascites was achieved in 22 out of 28 patients (78.6\%), PR was achieved in 2 patients (7.1\%), and no consequence was observed in 3 patients $(10.7 \%)$. Thus the total objective remission rate $(\mathrm{ORR}, \mathrm{ORR}=$ $\mathrm{CR}+\mathrm{PR}$ ) of this study was $85.7 \%$,;in the control group, the total objective remission rate was $33.3 \%$.The average KPS scores were significantly elevated by $16 \%$ from 62.8 before treatment to 72.3after HIPEC $(P<0.05)$. which demonstrated asignificant achievement on clinical efficacy with our modified HIPEC (Table2 and Table 3).

Observed toxicity. Nausea and vomiting, bone marrow suppression, diarrhea and constipation and liver and kidney

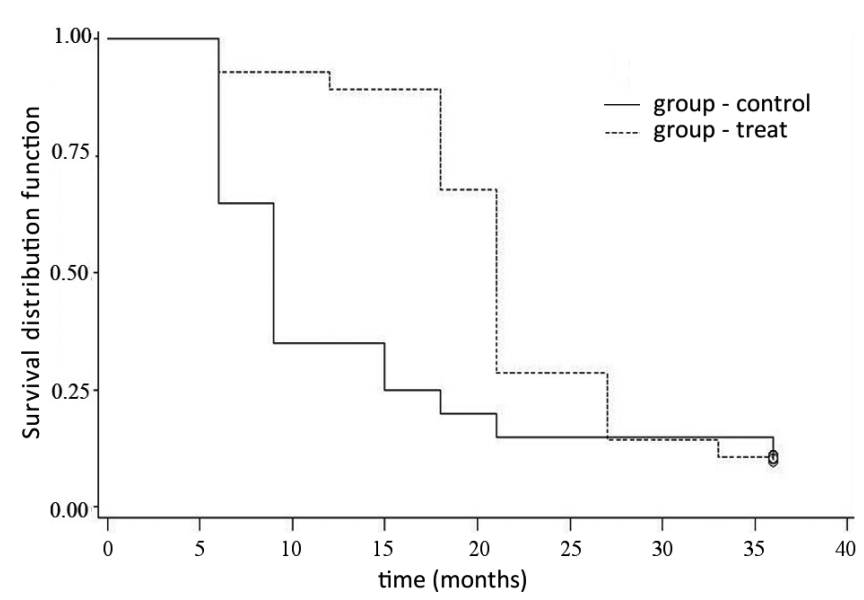

Figure 2. The median OS in the hyperthermic perfusion group (21 months) was significantly different from that in the control group ( 9 months) ( $P$ $<0.05)$.

damage were observed, and the results were not significantly different between the two groups $(\mathrm{P}>0.05)$ (Table 4$)$.

The survival time of the patients in the two groups. The median PFS in the hyperthermic perfusion group (12 months) was significantly different from that in the control group (6 months) $(\mathrm{P}<0.05)$. In the hyperthermic perfusion group, 25 patients were alive after 1 year ( 1 -year survival rate $=89.3 \%$ ), and in the control group, 8 patients were alive after 1 year ( 1 -year survival rate $=36.4 \%$ ); the 1 -year survival rates were significantly different $(\mathrm{P}<0.05)$. In the hyperthermic perfusion group, 3 patients were alive after 3 years ( 3 -year survival rate $=$ $10.7 \%$ ), and in the control group, 2 patients were alive after 3 years (3-year survival rate $=10.0 \%)$; the 3 -year survival rates were not significantly different $(\mathrm{P}>0.05)$. The median $\mathrm{OS}$ in the hyperthermic perfusion group (21 months) was significantly different from that in the control group (9 months) ( $\mathrm{P}$ $<0.05$ ) (Table 5, Figure 1 and Figure 2).

Table 2. Treatment efficacy in the two groups

\begin{tabular}{lcccccc}
\hline Group & $\mathrm{n}$ & $\mathrm{CR}$ & $\mathrm{PR}$ & $\mathrm{SD}$ & $\mathrm{PD}$ & Overall efficacy \\
\hline $\begin{array}{l}\text { Control group } \\
\begin{array}{l}\text { Hyperthermic } \\
\text { perfusion group }\end{array}\end{array}$ & 20 & 2 & 4 & 8 & 6 & $30.0 \%$ \\
\hline
\end{tabular}

Table 3. KPS scores before and after treatment for the hyperthermic perfusion and control groups ( $t$ test)

\begin{tabular}{lcc}
\hline & Control group & $\begin{array}{c}\text { Hyperthermic perfusion } \\
\text { group }\end{array}$ \\
\hline Before treatment & $65.5 \pm 1.98$ & $62.8 \pm 1.84$ \\
After treatment & $60.5 \pm 7.6$ & $74.3 \pm 5.0$ \\
P value & $>0.05$ & $<0.05$ \\
\hline
\end{tabular}


Table 4. Occurrence of toxicity in the two groups $(P>0.05)$

\begin{tabular}{|c|c|c|c|c|c|c|c|c|c|c|c|c|}
\hline & \multicolumn{6}{|c|}{ Hyperthermic perfusion group } & \multicolumn{6}{|c|}{ Control group } \\
\hline & 0 & I & II & III & IV & III-IV percentage (\%) & 0 & I & II & III & IV & III-IV percentage (\%) \\
\hline Nausea and vomiting & 4 & 8 & 11 & 5 & 0 & 17.8 & 3 & 7 & 7 & 2 & 1 & 15.0 \\
\hline Bone marrow suppression & 6 & 6 & 10 & 4 & 2 & 21.4 & 5 & 6 & 7 & 3 & 1 & 20.0 \\
\hline Diarrhea and constipation & 13 & 6 & 5 & 2 & 2 & 14.3 & 8 & 4 & 6 & 1 & 1 & 10.0 \\
\hline Liver and kidney damage & 24 & 2 & 1 & 1 & 0 & 3.6 & 18 & 1 & 0 & 1 & 0 & 5.0 \\
\hline
\end{tabular}

Table 5. Patient survival in the two groups

\begin{tabular}{lccc}
\hline & $\begin{array}{c}\text { Hyperthermic } \\
\text { perfusion group }\end{array}$ & Control group & P value \\
\hline 1-year survival rate (\%) & 89.3 & 36.4 & $<0.05$ \\
3-year survival rate (\%) & 10.7 & 10.0 & $>0.05$ \\
Median PFS (months) & 12 & 6 & $<0.05$ \\
Median OS (months) & 21 & 9 & $<0.05$ \\
\hline
\end{tabular}

\section{Discussion}

Gastric cancer is one of the most common digestive malignancies and is not easy to identify at the early stage. Most patients are diagnosed at the advanced stage and often have abdominal or pelvic lymph node metastasis and/or omental transfer. Malignant ascites form easily and seriously affect patient survival and quality of life [1-3, 16, 17]. Intravenous chemotherapy is an important treatment for advanced gastric cancer, but the amount of drug that reaches the abdominal and pelvic cavity is limited, which hinders the efficacy of the chemotherapy [18-20].

Intraperitoneal hyperthermic chemoperfusion is a novel route of administering chemotherapy. Using this method, a markedly higher localized drug concentration near the tumor can be achieved compared with intravenous drug administration; furthermore, the extent of contact between the drug and the tumor can also be increased, thereby increasing drug penetration into the tumor. The vascular structure and microcirculation of normal tissue structures have a robust cooling ability, whereas tumor tissue lacks a proper blood circulation system. Therefore, the temperature of the tumor region is higher than the surrounding normal tissue. The heat from the treatment can further increase the temperature of the tumor region, thereby damaging cell membrane structures and promoting tumor cell death [21-22]. Masunaga suggested that hyperthermia interferes with the ability of tumor-associated genes to regulate the cellular intake and efflux of chemotherapy drugs; after hyperthermia, chemotherapy drug efflux from tumor cells decreases, and the accumulated concentration increases [23]. Studies have shown that tumor cells are exquisitely sensitive to heat. When the temperature stays at $43^{\circ} \mathrm{C}$ for $1 \mathrm{~h}$, tumor cells suffer irreversible damage; simultaneously, the temperature change can increase the activity of certain chemotherapy drugs [24].
Our results indicated that the efficacy of treating gastric malignant ascites with only systemic chemotherapy was $36.4 \%$, which was consistent with data from other related studies (8); however, the efficacy was much higher in the hyperthermic perfusion group (89.3\%) than in the control group, suggesting that intraperitoneal hyperthermic perfusion is effective at relieving malignant ascites caused by gastric cancer. There was no significant difference in toxicity between the two groups. The intraperitoneal hyperthermic perfusion treatment had a good safety profile. The hyperthermic perfusion patients mostly experienced abdominal pain and activity limitation, which were caused by the catheter incision and stimulation of the peritoneal drainage tube. The pain was within the tolerable range and was relieved soon after extubation. No sequelae adverse reactions were observed. Patients in the hyperthermic perfusion group had a better 1-year survival rate, median OS and median PFS than those in the systemic chemotherapy group, which may stem from the higher short-term efficacy. There was no difference in the 3-year survival rates, which could be due to the small sample size, and the survival advantage was therefore not adequate. Currently, our research group is collecting data on additional patients, and more objective and reliable survival data are expected.

In summary, intraperitoneal hyperthermic perfusion is a safe and effective treatment for patients with gastric cancer malignant ascites. These patients experienced an improvement in their quality of life, which had been decreased due to the ascites. Although the survival benefits associated with this technology require additional studies for confirmation, this technology is worthy of clinical application. Notably, in the clinic, we observed that intraperitoneal hyperthermic perfusion patients mostly had localized subcutaneous metastasis associated with the incision. Although this did not affect the quality of life of the patients, catheter placement technology must be improved to avoid localized tumor growth.

\section{References}

[1] BANDO E, YONEMURA Y, TAKESHITA Y, TANIQUCHI $\mathrm{K}$, YASUI T, et al. Intraoperative lavage for cytological examination in 1,297 patients with gastric carcinoma. Am J Surg. 1999; 178: 256-62. http://dx.doi.org/10.1016/S0002-9610 (99)00162-2

[2] SUGARBAKER PH, YONEMURA Y. Clinical pathway for the management of resectable gastric cancer with peritoneal 
seeding: best palliation with a ray of hope for cure. Oncology. 2000; 58: 96-107. http://dx.doi.org/10.1159/000012086

[3] SADEGHI B, ARVIEUX C, GLEHEN O, BEAUJARD AC, RIVORE M, et al. Peritoneal carcinomatosis from non-gynecologic malignancies: results of the EVOCAPE 1 multicentric prospective study. Cancer. 2000; 88: 358-63. http://dx.doi. org/10.1002/ (SICI) 1097-0142 (20000115)88:2<358::AIDCNCR16>3.0.CO;2-O

[4] TOPUZ E, BASARAN M, SAIP P, AYDINER A, ARQON $A$, et al. Adjuvant intraperitoneal chemotherapy with cisplatinum, mitoxantrone, 5-fluorouracil, and calcium folinate in patients with gastric cancer: a phase II study . Am J Clin Oncol. 2002; 25: 619-24. http://dx.doi.org/10.1097/00000421200212000-00019

[5] GESSON-PAUTE A, FERRON G, THOMAS F, DE LARA EC, CHATELUT E, et al. Pharmacokinetics of oxaliplatin during open versus laparoscopically assisted heated intraoperative intraperitoneal chemotherapy (HIPEC): an experimental study. Ann Surg Oncol. 2008; 15: 339-44. http://dx.doi.org/10.1245/ $\underline{\text { s10434-007-9571-9 }}$

[6] FACCHIANO E, SCARINGI S, KIANMANESH R, KIANMANESH R, SABATE JM, et al. Laparoscopic hyperthermic intraperitoneal chemotherapy (HIPEC) for the treatment of malignant ascites secondary to unresectable peritoneal carcinomatosis from advanced gastric cancer. Eur J Surg Oncol. 2008; 34: 154-8. http://dx.doi.org/10.1016/j. ejso.2007.05.015

[7] BAE JH1, LEE JM, RYU KS, LEE YS, PARK YG, HUR SY, AHN WS, NAMKOONG SE. Treatment of ovarian cancer with paclitaxel- or carboplatin-based intraperitoneal hyperthermic chemotherapy during secondary surgery. gynecol oncol, 2007, 106: 193-200

[8] P. DUBE, L. SIDERIS, C. LAW, L, et al. Guidelines on the use of cytoreductive surgery and hyperthermic intraperitoneal chemotherapy in patients with peritoneal surface malignancy arising from colorectal or appendiceal neoplasms. Curr Oncol. 2015; 22: e100-e112 http://dx.doi.org/10.3747/ co.22.2058

[9] EDWARD A, LEVINE, JOHN H. Stewart, IV, et al. Cytoreductive Surgery and Hyperthermic Intraperitoneal Chemotherapy for Peritoneal Surface Malignancy: Experience with 1,000 Patients. J Am Coll Surg. 2014 April; 218: 573-585 http://dx.doi.org/10.1016/j.jamcollsurg.2013.12.013

[10] GAROFALO A, VALLE M, GARCIA J AND SUGARBAKER $\mathrm{PH}$. Laparoscopic intraperitoneal hyperthermic chemotherapy for palliation of debilitating malignant ascites. Eur J Surg Oncol. 2006; 32: 682-5. http://dx.doi.org/10.1016/j. ejso.2006.03.014

[11] BA MC, CUI SZ, LIN SQ, TANG YQ, WU YB, et al. Chemotherapy with laparoscope-assisted continuous circulatory hyperthermic intraperitoneal perfusion for malignant ascites. World J Gastroenterol. 2010; 16: 1901-7. http://dx.doi. org/10.3748/wjg.v16.i15.1901

[12] FERRON G, GESSON-PAUTE A, CLASSE JM, QUERLEU D. Feasibility of laparoscopic peritonectomy followed by intra-peritoneal chemo-hyperthermia: an experimental study.
Gynecol Oncol. 2005; 99: 358-61. http://dx.doi.org/10.1016/j. ygyno.2005.06.043

[13] TRISTAN D YAN, CHRISTOPHER QIAN CAO, STINE MUNKHOLM-LARSEN. A pharmacological review on intraperitoneal chemotherapy for peritoneal malignancy World J Gastro in -test Oncol. 2010; 2: 109-116

[14] SUGARBAKER PH, MORA JT, CARMIGNANI P, et al: Update on chemotherapeutic agents utilized for perioperative intraperitonaeal chemotherapy. Oncologist 2005; 10: 112-122 http://dx.doi.org/10.1634/theoncologist.10-2-112

[15] SHUZHONG CUI, MINGCHEN BA, YUNQIANG TANG, JIFANG LIU, YINBING W2, et al. B ultrasound-guided hyperthermic intraperitoneal perfusion chemotherapy for the treatment of malignant ascites. Oncol Rep. 2012; 28: 1325-31.

[16] SHIMADA M, BERJOHN C, TANEN DA. Ascites as the initial presentation of gastrointestinal carcinoma. J Emerg Med. 2013; 44: 195-8. http://dx.doi.org/10.1016/j. jemermed.2012.02.060

[17] SAIF MW, SIDDIQUI IA, SOHAIL MA. Management of ascites due to gastrointestinal malignancy. Ann Saudi Med. 2009; 29: 369-7. http://dx.doi.org/10.4103/0256-4947.55167

[18] TAMEGAI H, KAIGA T, KOCHI M, FUJII M, KANAMORI $\mathrm{N}$, et al. Pharmacokinetics of docetaxel in gastric cancer patients with malignant ascites. Cancer Chemother Pharmacol. 2013; 71: 727-31. http://dx.doi.org/10.1007/s00280-012-2066-9

[19] HASOVITS C, CLARKE S. Pharmacokinetics and pharmacodynamics of intraperitoneal cancer. Clin Pharmacokinet. 2012; 51: 203-24. http://dx.doi.org/10.2165/11598890-000000000$\underline{00000}$

[20] VAN DER SPEETEN K, STUART OA, SUGARBAKER $\mathrm{PH}$. Using pharmacologic data to plan clinical treatments for patients with peritoneal surface malignancy. Curr Drug Discov Technol. 2009; 6: 72-81. http://dx.doi. org/10.2174/157016309787581084

[21] SAYAG-BEAUJARD AC, FRANCOIS Y, GLEHEN O, SADEQHI-LOOYEH B, BIENVENU J, et al. Treatment of peritoneal carcinomatosis in patients with digestive cancers with combination of intraperitoneal hyperthermia and mitomycin C. Bull Cancer. 2004; 91: 113-32.

[22] YANG XJ, LI Y, YONEMURA Y. Cytoreductive surgery plus hyperthermic intraperitoneal chemotherapy to treat gastric cancer with ascites and/or peritoneal carcinomatosis: Results from a Chinese center. J Surg Oncol. 2010; 101: 457-64. http:// dx.doi.org/10.1002/jso.21519

[23] MASUNAGA S, TAKAHASHI A, OHNISHI K, OHNISHI T, NAGATA K, et al. Effects of mild temperature hyperthermia and p53 status on the size of hypoxic fractions in solid tumors, with reference to the effect in intratumor quiescent cell populations. Int J Radiat Oncol Biol Phys. 2004; 60: 570-7. http://dx.doi.org/10.1016/j.ijrobp.2004.05.002

[24] CHOI EK, PARK SR, LEE JH, CHUNG HS, AHN HE, et al. Induction of apoptosis by carboplatin and hyperthermia alone or combined in WERI human retinoblastoma cells. Int J Hyperthermia. 2003; 19: 431-43. http://dx.doi. org/10.1080/0265673021000017118 